\title{
FACTORS OF AFFECTING THESIS COMPLETION BY USING CHAID METHOD BASED ON GENDER
}

\author{
Haida Fitri \\ Fakutlas Tarbiyah dan Ilmu Keguruan, IAIN Bukittinggi, baidanabibi@gmail.com \\ Aniswita \\ Fakutlas Tarbiyah dan Ilmu Keguruan, LAIN Bukittinggi, anesa.mq81@gmail.com \\ Charles \\ Fakutlas Tarbiyah dan Ilmu Keguruan, LAIN Bukittinggi, charlesmalinkayo@gmail.com
}

Diterima: 24 Januari $2019 \quad$ Direvisi:15 Mei $2019 \quad$ Diterbitkan: 30 Juni 2019

\begin{abstract}
Thesis as one of the requirements to obtain a bachelor degree, ideally it can be completed in one semester, but many students finish the thesis more than the allocated time. This condition is caused by many factors including gender differences; male and female students have many differences especially in the allocation of time to finish a thesis. This research aimed to find out the factors that influence the time needed to finish a thesis and the classification of these factors based on their gender. The factors observed were GPA, gender and competence of the supervisor, types of research used, source of the data and technique of the data collection. The statistical analysis used was the CHAID method. The result of this study showed that out of 387 male students who have graduated in period I to VI, it was found that the factors which influence them to finish their thesis were GPA. While for female students, out of 1150 data, three factors that influence them were major, sources of data and expertise areas of the main supervisors. Moreover, three characteristics of students who finish thesis longer than 6 months were male students with a GPA less than 3,34, female students from Islamic Education/English Department/Math Department with the source primary/ secondary data or others, and female students from guidance and couceling department by the psychologist's/ others as main supervisor.
\end{abstract}

Keywords: Thesis, Allocated Time to Finish Thesis, CHAID Method.

\begin{abstract}
Abstrak
Skripsi sebagai salah satu syarat untuk memperoleh gelar sarjana idealnya dapat dituntaskan dalam waktu satu semester, namun banyak mahasiswa yang menyelesaikan lebih dari waktu yang telah ditetapkan. Kondisi ini dipicu oleh banyak faktor termasuk di dalamnya jenis kelamin, antara mahasiswa laki-laki dan perempuan memiliki banyak perbedaan termasuk dalam menyelesaikan skripsi. Tujuan dari penelitian ini adalah untuk mengetahui faktor-faktor yang memengaruhi masa penyelesaian skripsi dan klasifikasi faktor-faktor tersebut baik untuk mahasiswa laki-laki maupun mahasiswa perempuan. Faktor-faktor yang diamati adalah IPK, jenis kelamin dan bidang keahlian dosen pembimbing, jenis penelitian, sumber data dan teknik pengambilan data. Analisis statistik yang digunakan adalah metode CHAID. Hasil penelitian ini memperlihatkan bahwa dari 387 orang mahasiswa laki-laki yang telah diwisuda pada periode I sampai dengan VI, diperoleh faktor yang mempengaruhi masa penyelesaian skripsinya adalah IPK. Sedangkan untuk mahasiswa perempuan, dari 1150 data diperoleh tiga faktor yang mempengaruhi secara berturut-turut yaitu program studi, sumber data dan bidang keahlian dosen pembimbing utama. Disamping itu diperoleh tiga karakteristik mahasiswa yang diduga $>6$ bulan dalam menyelesaian skripsinya, yaitu mahasiswa laki-laki dengan IPK $<3,34$, mahasiswa perempuan dari prodi PAI/PBI/PMTK dengan sumber data primer/sekunder/lain-lain dan mahasiswa perempuan dengan prodi BK yang dibimbing oleh dosen pembimbing utama psikolog/lain-lain.
\end{abstract}

Kata Kunci: Skripsi, Masa Penyelesaia Skripsi, Metode CHAID. 


\section{Latar Belakang}

Perkembangan ilmu pengetahuan dan teknologi tidak akan pernah lepas dari peran penelitian, baik penelitian yang dilakukan oleh para ilmuwan di lembaga-lembaga penelitian, maupun penelitian yang dilakukan oleh dosen dan mahasiswa di perguruan tinggi. Setiap calon sarjana wajib melaksanakan penelitian sebagai salah satu syarat untuk mencapai gelar akademiknya. Penelitian yang dilakukan disajikan dalam bentuk karya ilmiah dan harus dipertanggung jawabkan pada akhir program pendidikan. ${ }^{1}$ Karya ilmiah yang dihasilkan tersebut adalah skripsi. Skripsi adalah karya ilmiah yang ditulis berdasarkan hasil penelitian lapangan atau penelitian kepustakaan dan dipertahankan di depan sidang ujian (munaqasyah) dalam rangka menyelesaikan studi strata tingkat satu (S1) untuk memperoleh gelar sarjana. ${ }^{2}$

Di dalam kurikulum program studi, pembuatan skripsi semestinya dapat dituntaskan dalam rentang waktu satu semester (enam bulan), namun pada kenyataannya banyak mahasiswa yang tidak mampu menyelesaikan skripsi sesuai dengan waktu yang telah ditetapkan. Hal ini, disebabkan oleh banyak faktor, baik dari dalam diri mahasiswa itu sendiri maupun dari lingkungannya.

Menurut Agnes Maria Polina dan Jong Jek Siang, terdapat dua faktor yang menyebabkan waktu penyelesaian skripsi lebih lama, yaitu faktor internal dan ekternal. Dua hal yang menjadi penyebab utama dari faktor internal adalah rendahnya motivasi dan kemampuan akademik dari mahasiswa tersebut, sedangkan faktor eksternal

1 Asih Anggarani, dkk, (2006), Mengasah Keterampilan Menulis Ilmiah di Perguruan Tinggi, Yogyakarta: Graha Ilmu, 145

2 IAIN Bukittinggi,(2015), Pedoman Penulisan Tugas Akhir dan Skripsi, Bukittinggi: LPM IAIN Bukittinggi, 15 diantaranya adalah sulitnya materi atau judul skripsi yang dikerjakan, sulitnya pencarian literatur atau data, permasalahan dengan dosen pembimbing, faktor lingkungan dan lain-lain. ${ }^{3}$

Dalam Dian Cahyawati S dkk menyatakan bahwa perbedaan masa penyelesaian skripsi mahasiswa dipengaruhi oleh berbagai faktor antara lain prestasi akademik yang diukur dengan Indeks Prestasi Akademik (IPK), jenis kelamin mahasiswa, topik/bidang penelitian yang dikaji, jenis data yang digunakan dalam penelitian, dan jenis kelamin dosen pembimbing juga memiliki pengaruh terhadap masa penyelesaian skripsi. Jadi salah satu faktor yang di duga mempengaruhi masa penyelesaian skripsi mahasiswa adalah jenis kelamin mahasiswa.

Menurut John W. Santrock peran jenis kelamin/ gender adalah seperangkat ekspektasi yang mengatur bagaimana laki-laki atau perempuan seharusnya berpikir, bertindak dan merasakan. ${ }^{5}$ Seorang Psikolog pendidikan Jeanne ellis ormrod menyatakan persoalan perbedaan gender dalam kecerdasan atau pencapaian akademis diperdebatkan selama berabad-abad. Para peneliti telah mengidentifikasi sejumlah perbedaan dalam bidang fisik, kognitif, pribadi dan sosial, yaitu sebagai berikut.

Aktivitas Fisik dan Keterampilan Motorik.

Anak perempuan secara temperamental cenderung pasif jika dibandingkan dengan anak laki-laki, anak perempuan pada umumnya lebih suka duduk tenang dalam waktu yang lama,

${ }^{3}$ Agnes Maria Polina dan Jong Jek Siang,(2009), Cara Cepat Menyusun Skripsi, Yogyakarta: Andi, 3-5

${ }^{4}$ Dian Cahyawati S., Susi Yohana, dan Putera B.J. Bangun, (2013), Aplikasi Metode CHAID dalam Menganalisis Keterkaitan Faktor Risiko Lama Penyelesaian Skripsi Mahasiswa, Yogyakarta: Pendidikan Matematika FMIPA UNY, Prosiding, 47

${ }^{5}$ John W. Santrock., (2014), Psikologi Pendidikan (edisi 5 Buku 1), Jakarta:Salemba Humatika, 184.

'Jeanne ellis Ormrod., (2008), Psikolog Pendidikan, Jakarta: Erlangga, 175 
suka membaca dan lebih tajam dalam keterampilan motorik halusnya sedangkan anak laki-laki lebih mengembangkan keterampilan fisik dan motorik mereka melalui partisipasi olahraga yang terorganisir.

Kemampuan kognitif dan akademisi.

Rata-rata anak laki-laki dan perempuan memiliki potensi yang sama dalam tes intelegensi umum, hal yang membedakan terdapat pada kemampuan visual-spasial, anak laki-laki lebih baik dalam hal ini sedangkan anak perempuan lebih mampu dalam beberapa keterampilan verbal. Dalam bidang sains pada tahun 2005 tren di Amerika Serikat pencapaian nilai sains anak laki-laki sedikit lebih baik dibandingkan dengan anak perempuan di kelas 4, 8 dan 12. Hal yang sama juga diperoleh pada studi lain untuk kelas 8 dan 10. Sedangkan untuk kelas sains yang menekankan pada kegiatan laboratorium hasil anak perempuan cukup membaik.

Motivasi dalam kegiatan akademis

Secara umum anak perempuan lebih peduli untuk berprestasi tinggi, aktif dalam kegiatan kelas dan lebih rajin dalam mengerjakan tugas-tugas di sekolah, sedangkan anak laki-laki lebih suka mengambil tantangan dan resiko akademis.

Perasaan diri

Pada masa remaja, persepsi diri anak laki-laki dan perempuan juga cenderung sesuai dengan stereotip terkait dengan bidang yang dikuasainya. Anak laki-laki cenderung menilai diri lebih tinggi dalam bidang matematika dan olahraga, dan anak perempuan lebih tinggi dalam membaca dan kajian sosial.

\section{Perilaku dan bubungan antar pribadi}

Anak laki-laki cenderung kompetitif sedangkan anak perempuan lebih mudah lebur dan bekerjasama.

Perilaku di kelas

Di dalam kelas anak laki-laki lebih banyak berbicara dan bertanya, kadang tanpa

${ }^{7}$ John W. Santrock., 186-187. menunggu ditunjuk sedangkan anak perempuan cenderung sebagai partisipan, kurang suka menawarkan ide dengan sukarela karena mungkin takut kelihatan bodoh atau khawatir apabila terlihat selalu cerdas yang mengakibatkan mengurangi popularitasnya.

Aspirasi Karir

Secara historis, hasrat anak laki-laki dalam karir lebih ambisius dari pada anak perempuan.

Jadi berdasarkan uraian di atas anak laki-laki dan perempuan memiliki kesulitan yang berbeda, minat dan cara menyikapi suatu masalah dengan cara yang berbeda juga.

Berdasarkan data yang penulis dapatkan di salah satu program studi FTIK IAIN Bukittinggi, dimana FTIK IAIN Bukittinggi merupakan salah satu fakultas yang memiliki jumlah mahasiswa yang cukup banyak dengan enam program studinya yaitu, Pendidikan Agama Islam (PAI), Pendidikan Bahasa Arab (PBA), Pendidikan Bahasa Inggris (PBI), Pendidikan Matematika (PMTK), Pendidikan Teknik dan Ilmu Komputer (PTIK) dan Bimbingan Konseling (BK). Diketahui rata-rata masa penyelesaian skripsi mahasiswa PMTK yang lulus pada periode I (April 2015) sampai dengan periode VI (Oktober 2017) adalah 7,68 bulan. Dari 214 mahasiswa lulusan PMTK terdapat 99 orang atau $46,26 \%$ yang mampu menyelesaikan skripsi kurang atau sama dengan 6 bulan sedangkan sisanya $54,74 \%$ melebihi dari target waktu normal. Hal ini memperlihatkan bahwa bahwa banyak mahasiswa lulusan PMTK yang masa penyelesaian skripsinya lebih dari 6 bulan.

Lebih lanjut dilihat dari masa penyelesaian skripsi berdasarkan gender, untuk mahasiswa PMTK angkatan 2011 dari 10 mahasiswa PMTK yang berjenis kelamin lakilaki yang telah diwisuda terdapat 6 orang mahasiswa yang mampu menyelesaikan skripsi $\leq 6$ bulan sedangkan sisanya 4 orang menyelesaikan skripsi melebihi waktu 6 bulan. Sedangkan untuk mahasiswa yang berjenis 
kelamin perempuan dari 53 orang mahasiswa terdapat 24 mahasiswa yang masa penyelesaian skripsinya cepat atau tepat waktu sedangkan 29 orang nya melebihi dari rentang waktu yang ditargetkan. Untuk lebih jelasnya dapat dilihat pada Tabel 1.

Tabel 1. Masa Penyelesaian Skripsi Lulusan PMTK Angkatan 2011

\begin{tabular}{|l|l|l|l|l|l|}
\hline \multirow{2}{*}{$\begin{array}{l}\text { Jenis } \\
\text { Kelamin }\end{array}$} & \multirow{2}{*}{$\begin{array}{l}\text { Jum } \\
\text { Mahasiswa }\end{array}$} & \multirow{2}{*}{$\begin{array}{l}\text { mhs } \\
\text { mhs }\end{array}$} & \multicolumn{3}{|l|}{ Masa penyelesaian skripsi } \\
\cline { 3 - 7 } & & $\begin{array}{l}\text { jum bulan } \\
\text { lah }\end{array}$ & \multicolumn{3}{l}{$\mathbf{3}$ 6 bulan } \\
\hline Perempuan & 53 & 24 & 45,28 & 29 & 54,72 \\
\hline Laki-Laki & 10 & 6 & 60,00 & 4 & 40,00 \\
\hline Total & 65 & 30 & 46,15 & 33 & 53,85 \\
\hline
\end{tabular}

Sumber: Program studi pendidikan matematika FTIK LAIN Bukittinggi

Dari Tabel 1, dapat dilihat bahwa pada angkatan 2011, mahasiswa laki-laki lebih banyak yang mampu menyelesaikan skripsinya cepat atau tepat waktu dari pada mahasiswa berjenis kelamin perempuan yaitu 60\% berbanding 45,28\%.

Untuk mengetahui lebih banyak mengenai hambatan mahasiswa selama mengerjakan skripsi, maka penulis melakukan wawancara pada beberapa orang mahasiswa yang telah mengikuti ujian munaqasah. Dari wawancara tersebut, diketahui bahwa hambatan secara umum yang mereka alami ketika mengerjakan skripsi ialah sulitnya menemukan referensi buku yang tepat, kurangnya pemahaman terhadap metode yang digunakan dalam penelitian, dan kesulitan dalam pengolahan data serta kesulitan menemui dosen pembimbing. Sedangkan bagi mahasiswa berjenis kelamin laki-laki mengakui bahwa salah satu hambatan dalam menyelesaiakan skripsi adalah menentukan judul skripsi atau topik akan diteliti dan masih banyaknya kuliah yang harus diulang disamping kendala-kendala umum di atas.

Untuk mengetahui faktor-faktor yang mempengaruhi masa penyelesaian skripsi dan melihat hubungan antar faktor-faktor tersebut baik untuk mahasiswa berjenis kelamin perempuan maupun untuk mahasiswa berjenis kelamin laki-laki diperlukan suatu metode statistik yang tepat. Salah satunya adalah metode CHAID (Chi-Square Automatic Interaction Detection).

Menurut Gallagher, CHAID adalah sebuah teknik iterasi yang menguji satu persatu variabel bebas yang digunakan dalam klasifikasi, dan menyusunnya berdasarkan pada tingkat signifikasi statistiknya terhadap variabel terikatnya. ${ }^{8}$ Hasil dari pengklasifikasian dengan metode CHAID disajikan dalam diagram pohon. Menurut Myers dalam yohanes sondang kunto dkk, Langkah metode CHAID diawali dengan memilih variabel-variabel bebasnya atas dasar uji chi-square antara variabel-variabel bebas yang tersedia berikut dengan kategori-kategorinya dengan kategorikategori variabel terikatnya. ${ }^{9} \mathrm{Uji}$ chi-square merupakan uji non parametrik, uji ini tidak mengharuskan adanya uji prasyarat dan uji ini cocok untuk penelitian ini karena memiliki data yang banyak dan memiliki tipe data yang beragam sehingga membuat data ini lebih bermakna.

Berdasarkan uraian di atas, maka penulis tertarik untuk mengetahui klasifikasi faktor-faktor yang mempengaruhi Waktu Penyelesaian Skripsi Mahasiswa Fakultas Tarbiyah Dan Ilmu Keguruan (FTIK) IAIN Bukittinggi Dengan Metode CHAID untuk mahasiswa berjenis kelamin laki-laki dan perempuan.

Hasil penelitian ini diharapkan dapat menjadi bahan pertimbangan untuk meminimalisir keterlambatan dalam

${ }^{8}$ Cecily A. Gallagher, dkk, an Iterative Approach To Classification Analysisi, http://www.Casact.org/pubs/dpp/dpp90/90dpp237. pdf (diakses 13 maret 2017). 242

9 Yohanes Sondang Kunto dan Siti Nurul Hasana, (2006), Analisis CHAID Sebagai Alat Bantu Statistika Untuk Segmentasi Pasar, Jurnal Manajemen Pemasaran Vol. 1 No 2. 89. 
penyelesaian skripsi baik bagi mahasiswa lakilaki maupun bagi mahasiswa perempuan, sehingga hal ini juga berdampak untuk waktu kelulusan mahasiswa tersebut nantinya.

\section{Metodologi Penelitian}

Metode penelitian yang digunakan adalah metode deskriptif dengan studi korelasi faktor-faktor yang mempengaruhi waktu penyelesaian skripsi mahasiswa berjenis kelamin laki-laki dan faktor-faktor yang mempengaruhi waktu penyelesaian skripsi bagi mahasiswa perempuan.

Variabel terikat dalam penelitian ini adalah Masa Penyelesaian Skripsi (MPS). Masa penyelesaian skripsi adalah rentang waktu yang dibutuhkan oleh masing-masing mahasiswa dalam menyelesaikan skripsi. Rentang ini dihitung sejak bimbingan pertama sampai disetujui untuk munaqasah atau mulai observasi awal dilakukan hingga sidang sarjana dan dinyatakan lulus melalu surat keputusan yudisium FTIK IAIN Bukittinggi.

Masa Penyelesaian Skripsi dikategorikan menjadi dua kategori, yaitu; kategori I: kurang atau sama dengan 6 Bulan ( $\leq 6$ bulan); kategori II: Lebih dari 6 bulan ( $>6$ bulan). Variabel-variabel bebas yang diamati dapat dilihat pada Tabel 2 berikut;

Tabel 2 Variabel Bebas yang diamati

\begin{tabular}{|c|c|c|c|}
\hline No & $\begin{array}{l}\text { Nama } \\
\text { Variabel } \\
\text { (Notasi) }\end{array}$ & Tipe & Kategori \\
\hline \multirow{3}{*}{1} & \multirow{3}{*}{$\begin{array}{l}\text { Indeks Prestasi } \\
\text { Kumulatif } \\
\text { (IPK) }\end{array}$} & \multirow{3}{*}{$\begin{array}{l}\text { Ordi } \\
\text { nal }\end{array}$} & $1: 3,34-4,00$ \\
\hline & & & $2: 2,76-3,33$ \\
\hline & & & $3: 2,00-2,75$ \\
\hline \multirow{5}{*}{2} & \multirow{5}{*}{$\begin{array}{l}\text { Jenis Penelitian } \\
\text { (JP) }\end{array}$} & \multirow{5}{*}{$\begin{array}{l}\text { Nomi } \\
\text { nal }\end{array}$} & 1: Kuantitatif \\
\hline & & & 2: Kualitatif \\
\hline & & & 3: Gabungan \\
\hline & & & 4:Studi Pustaka \\
\hline & & & $\begin{array}{l}\text { 5:Pengembanga } \\
\mathrm{n} \text { atau PTK }\end{array}$ \\
\hline 3 & Jenis Kelamin & Nomi & 1: Laki-laki \\
\hline
\end{tabular}


Tabel 3 Sebaran data lulusan mahasiswa Fakultas Tarbiyah dan Ilmu Keguruan IAIN Bukittinggi Berdasarkan Gender

\begin{tabular}{|l|l|l|}
\hline Prodi JK & $\begin{array}{l}\text { Laki } \\
\text { Laki }\end{array}$ & Perempuan \\
\hline PAI & 111 & 244 \\
\hline PBA & 16 & 40 \\
\hline PBI & 31 & 150 \\
\hline PMTK & 24 & 190 \\
\hline PTIK & 163 & 301 \\
\hline BK & 42 & 225 \\
\hline Total Sumber: AKAMA LAIN Bukittinggi
\end{tabular}

Keterangan:

$\begin{array}{ll}\text { JK } & \text { : Jenis Kelamin } \\ \text { PAI } & \text { : Pendidikan Agama Islam. } \\ \text { PBA } & \text { : Pendidikan Bahasa Arab. } \\ \text { PBI } & \text { : Pendidikan Bahasa Inggris. } \\ \text { PMtk } & \text { : Pendidikan Matematika. } \\ \text { PTIK } & : \text { Pendidikan Teknik dan Ilmu } \\ & \text { Komputer. } \\ \text { BK } & : \text { Bimbingan dan Konseling. }\end{array}$

Untuk mengetahui faktor-faktor yang mempengaruhi masa penyelesaian skripsi baik untuk mahasiswa laki-laki maupun perempuan, maka data yang diperoleh diolah dengan menggunakan Algoritma Metode CHAID.

Sebelum pengolahan data dengan algoritma CHAID, terlebih dahulu kita harus mendefinisikan tipe masing-masing variabel bebas. Gallagher mengungkapkan dalam CHAID ada tiga tipe data yaitu pertama tipe Monotik, kategori-kategori pada tipe data ini dapat digabungkan oleh CHAID apabila keduanya pada urutan yangberdekatan satu sama lainnya, kedua tipe Bebas, kategorikategori tipe data ini dapat digabungkan tanpa memperhatikan urutannya, dan tipe terakhir yaitu, Mengambang (floating) kategori-kategori variabel ini diperlakukan seperti tipe monotik kecuali untuk katgeori yang terakhir yaitu missing value yang dapat dikombinasikan dengan kategori manapun. ${ }^{10}$

${ }^{10}$ Yohanes ... h. 89-90.
Algortima Metode CHAID yang disajikan dalam artikel Dr. Kass pada tahun 1980 dalam Cecily A Gallagher adalah;

Tahap pertama, Untuk setiap prediktor (variabel bebas) lakukan tabulasi silang antara kategori-kategori prediktor (variabel bebas) dengan kategori-kategori variabel terikat dan kemudian lakukan tahap 2 dan 3.

Tahap kedua, Carilah pasangan kategori prediktor (pertimbangkan dalam menggabungkan kategori sesuai dengan sifat dari masing-masing tipe variabelnya) dimana $2 \times d$ sub tabelnya paling tidak berbeda secara signifikan. Jika nilai signifikannya tidak mencapai nilai kritis, gabungkan kedua kategori tersebut sehingga menjadi kategori tunggal dan ulangi langkah ini.

Tahap Ketiga, Untuk setiap kategori gabungan yang terdiri atas tiga atau lebih kategori asli, temukan pemecah biner yang paling signifikan sehingga gabungan dapat dipecah kembali. Apabila signifikansi diluar nilai kritis maka pisahkan kategori gabungan ini dan kembali ke tahap kedua.

Tahap keempat, Hitunglah signifikan dari setiap prediktor yang digabungkan secara optimal dan pilih yang paling signifikan. Apabila nilai signifikanya lebih besar dari nilai kritis, maka bagi data sesuai dengan kategori (kategori gabungan) dari prediktor yang dipilih tadi.

Tahap kelima, Untuk setiap partisi data yang belum dianalisis kembali ke tahap pertama. Langkah ini dapat dimodifikasi dengan mengecualikan dari partisi analisis lebih lanjut dengan sejumlah kecil pengamatan. ${ }^{11}$

Sedangkan langkah-langkah metode CHAID menurut Magidson dan Bagozzi dalam yohanes secara garis besar terbagi atas tiga tahap yairu penggabungan, pemisahan dan penghentian. Penjelasan dari masing-masing tahap tersebut adalah sebagai berikut: ${ }^{12}$

\footnotetext{
${ }^{11}$ Cecily A Gallagher ... 41-42

12 Yohanes... 90-92
} 


\section{Penggabungan.}

Untuk setiap variabel bebasnya bentuk tabel kontigensi dua arah antara kategorikategori variabel tersebut dengan kategorikategori variabel terikatnya.

Pecah masing-masing tabel kontigensi menjadi subtabel kontigensi dengan ukuran $2 \times j$ dengan $j$ adalah banyak kategori pada variabel terikat, kemudian untuk menguji kebebasannya terhadap varaibel terikatnya maka hitung nilai chi-square nya,

Rumusan hipotesisnya ialah:

$\mathrm{H}_{0}$ : Tidak terdapat hubungan antara kategori $i$ pada variabel independen dan kategori $j$ pada variabel dependen.

$\mathrm{H}_{1}$ : Terdapat hubungan antara kategori $i$ pada variabel independen dan kategori $j$ pada variabel dependen dengan rumus

$$
\chi^{2}=\sum_{i=1}^{a} \sum_{j=1}^{b} \frac{\left(n_{i j}-E_{i j}\right)^{2}}{E_{i j}}
$$

di mana

$$
E_{i j}=\frac{n_{i \cdot n \cdot j}}{n}
$$

Keterangan:

$\chi^{2}=$ nilai Chi-Square

$\mathrm{n}_{\mathrm{ij}}=$ nilai observasi atau banyaknya pengamatan pada baris ke-i dan kolom ke-j

$\mathrm{E}_{\mathrm{ij}}=$ nilai harapan (expected) pengamatan pada baris ke-i dan kolom ke-j

$\mathrm{n}_{\mathrm{i}}$. $=$ jumlah atau total banyaknya pengamatan pada baris ke- $i$

$\mathrm{n}_{\mathbf{j}}=$ jumlah atau total banyaknya pengamatan kolom ke-j

$\mathrm{n}=$ total banyaknya responden ${ }^{13}$

Mencari harga $\chi_{\alpha ; d b}^{2}$ dari tabel $c h i$ square dengan $\alpha=0,05$ dan $d b=(a-1)(b-1)$; dimana $a$ adalah banyak kategori variabel bebasnya dan $b$ banyak kategori variabel terikat.

\section{Kriteria Pengujian}

$$
\mathrm{H}_{0} \text { ditolak, jika } \chi^{2}>\chi^{2}{ }_{\alpha ; d b}
$$

13 Edi Riadi, (2016), Statistika Penelitian (Analisis Manual dan IBM SPSS), Yogyakarta: Andi, h. 379
Hitunglah $p$-value untuk masingmasing $\chi^{2}$. Diantara pasangan-pasangan yang tidak signifikan, gabungan pasangan kategori yang paling mirip atau yang memiliki $\chi^{2}$ terkecil menjadi kategori gabungan kemudian lanjut ke langkah 4, tetapi apabila semua pasangan signifikan maka lanjutkan ke langkah 5.

Untuk kategori gabungan yang terdiri atas 3 kategori atau lebih, periksalah kesignifikan kategori gabungan ini dengan kategori lainnya dalam variabel bebas. Apabila nilai $\chi^{2}$ nya signifikan maka kategori gabungan tersebut dipisah dengan kategori yang lain, namun apabila ada pasangan kategori gabungan lainnya yang juga signifikan maka pilih kategori yang memiliki $\chi^{2}$ tertinggi. Kemudian ulangi langkah 3.

Dengan cara memilih, gabungan suatu kategori yang mempunyai sedikit pengamatan yang tidak sesuai dengan kategori lain yang paling mirip. ( $\chi^{2}$ terkecil)

Hitung $p$-value terkoreksi Bonferoni.

$$
1-(1-\alpha)^{\mathrm{M}}>\alpha
$$

Keterangan:

$\mathrm{M}=$ pengali Bonferroni

$\alpha=$ salah tipe 1

Pengali Bonferroni untuk masingmasing tipe variabel-variabel independen adalah berbeda. Gallagher menyebutkan bahwa pengali Bonferroni untuk masing-masing jenis variabel independen adalah sebagai berikut:

Variabel independen monotonik (ordinal);

$$
\mathrm{M}=\left(\begin{array}{l}
c-1 \\
r-1
\end{array}\right)
$$

Variabel independen bebas (nominal);

$$
\mathrm{M}=\sum_{i=0}^{r-1}(-1)^{i} \frac{(r-i)^{c}}{i !(r-i) !}
$$

Variabel independen mengambang (floating);

$$
\mathrm{M}=\left(\begin{array}{l}
c-2 \\
r-2
\end{array}\right)+r\left(\begin{array}{l}
c-2 \\
r-1
\end{array}\right)
$$

Keterangan: 
$\mathrm{M}=$ pengali Bonferroni

c = banyaknya kategori variabel independen awal

$r=$ banyaknya kategori variabel independen setelah penggabungan ${ }^{14}$

\section{Pemisahan}

Pilihlah variabel bebas terbaik yaitu dengan $p$-value terendah jika tidak ada nilai $p$ value yang signifikan maka pemisahan tidak dapat dilakukan dan dinyatakan sebagai terminal simpul.

\section{Penghentian}

Kembali ke Tahap 1 untuk menganalisis sub kelompok berikutnya. Hentikan ketika semua sub kelompok telah dianalisis dan memiliki data yang sedikit.

Hasil perhitungan metode CHAID ini disajikan dalam bentuk diagram pohon seperti pada Gambar 1, Menurut Myers dalam Yohanes Sondang Kunto dkk, diagram pohon mengikuti aturan dari atas ke bawah, pada diagram pohon ini dimulai dari kelompok induk (parent node) selanjutnya ke sub kelompok (child node) dan seterusnya sampai pada kelompok yang tidak terdapat percabangan lagi yang disebut juga sebagai terminal node.

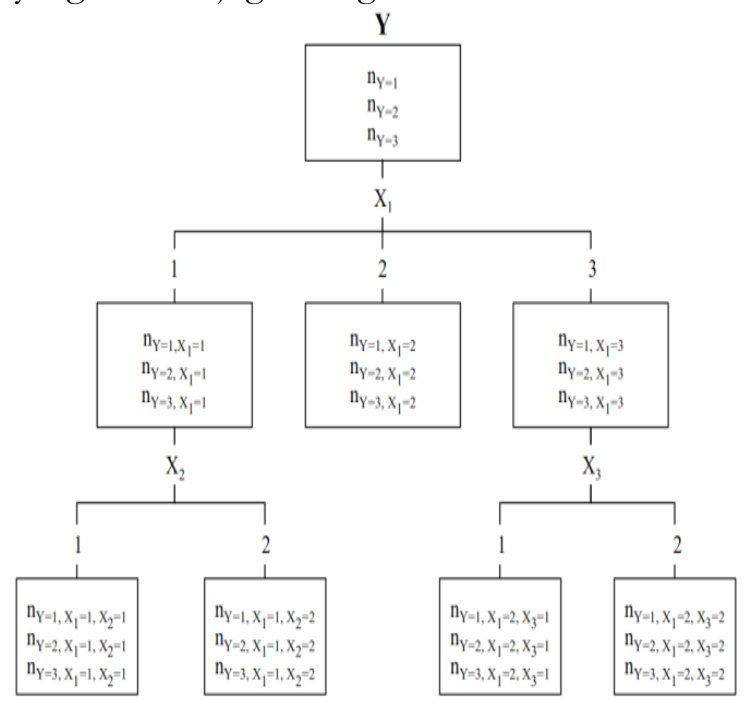

Gambar 1. Diagram Pohon dalam Analisis CHAID ${ }^{15}$

${ }^{14}$ Cecily A. Gallagher, ..., h. 247

15 Lehmann, Dietrich Eherler \& Thomas. Responder Profiling with CHAID and Dependency Analysis. https://pdfs.semanticscholar.org/4536/a9350179566c6

\section{Analisis CHAID Faktor-Faktor Yang Memengaruhi Waktu Penyelesaian Skripsi Mahasiswa Laki-Laki}

Data yang digunakan untuk melihat faktor-faktor yang mempengaruhi waktu penyelesaian skripsi pada mahasiswa laki-laki adalah sebanyak 387 orang mahasiswa FTIK IAIN Bukittinggi yang telah diwisuda pada periode I sampai dengan VI, dengan mengolah data karakteristik skripsi sesuai dengan variabel bebas yang digunakan. Untuk deskripsi singkat dari data tersebut dapat di lihat pada Tabel 4.

Berdasarkan Tabel 4 dapat disimpulkan bahwa waktu penyelesaian skripsi bagi mahasiswa laki-laki lebih banyak berada pada kategori > 6 bulan yaitu sebanyak 55,7 \% dengan IPK pada kategori 2 atau 3.33 - 2.76 sebanyak 134 orang. Karakteristik skripsi bagi lulusan berjenis kelamin laki-laki adalah sebagai berikut jenis penelitian yang paling banyak diminati adalah penelitian pengembangan atau PTK (peneltitian tindakan kelas), sumber data yang digunakan primer, teknik pengambilan data berupa angket dan mahasiswa terbanyak terdapat pada program studi PTIK. Untuk karakteristik dosen pembimbing utama maupun pendamping terbanyak pada dosen berjenis kelamin laki-laki dengan bidang keahlian pendidikan umum untuk dosen pembimbing utama dan keahlian jurusan murni yang relevan dengan program studi untuk dosen pembimbing pendampingnya.

Tabel 4. Data Karakteristik Skripsi Mahasiswa Berjenis Kelamin Laki-Laki FTIK IAIN Bukittinggi

\begin{tabular}{|c|c|c|c|c|}
\hline \multirow{2}{*}{$\begin{array}{l}\text { variabel } \\
\text { bebas }\end{array}$} & \multirow[b]{2}{*}{ Kategori } & \multicolumn{2}{|c|}{ MPS } & \multirow[b]{2}{*}{ Total } \\
\hline & & $\begin{array}{l}<=6 \\
\text { bulan }\end{array}$ & $\begin{array}{l}>\quad 6 \\
\text { bulan }\end{array}$ & \\
\hline \multicolumn{2}{|c|}{ Total } & 173 & 214 & 387 \\
\hline \multirow{3}{*}{ IPK } & 1 & 91 & 79 & 170 \\
\hline & 2 & 81 & 134 & 215 \\
\hline & 3 & 1 & 1 & 2 \\
\hline
\end{tabular}

e47b0ff9b283457aa6c75b0.pdf (diakses tanggal 13 Agustus 2018) 


\begin{tabular}{|c|c|c|c|c|}
\hline \multirow{5}{*}{ JP } & 1 & 42 & 6 & 08 \\
\hline & 2 & 58 & 8 & 26 \\
\hline & 3 & 2 & 4 & 6 \\
\hline & 4 & 11 & 5 & 16 \\
\hline & 5 & 60 & 71 & 131 \\
\hline \multirow{2}{*}{ JKP 1} & 1 & 114 & 136 & 250 \\
\hline & 2 & 59 & 78 & 137 \\
\hline \multirow{2}{*}{ JKP 2} & 1 & 108 & 127 & 235 \\
\hline & 2 & 65 & 87 & 152 \\
\hline \multirow{4}{*}{ BKD 1} & 1 & 31 & 30 & 61 \\
\hline & 2 & 50 & 57 & 107 \\
\hline & 3 & 74 & 100 & 174 \\
\hline & 4 & 18 & 27 & 45 \\
\hline \multirow{4}{*}{ BKD 2} & 1 & 49 & 62 & 111 \\
\hline & 2 & 77 & 103 & 180 \\
\hline & 3 & 39 & 42 & 91 \\
\hline & 4 & 8 & 7 & 15 \\
\hline \multirow{4}{*}{ SD } & 1 & 82 & 112 & 194 \\
\hline & 2 & 5 & 5 & 10 \\
\hline & 3 & 25 & 20 & 45 \\
\hline & 4 & 61 & 77 & 138 \\
\hline \multirow{5}{*}{ TPD } & 1 & 19 & 32 & 51 \\
\hline & 2 & 72 & 96 & 168 \\
\hline & 3 & 24 & 22 & 46 \\
\hline & 4 & 41 & 55 & 96 \\
\hline & 5 & 17 & 9 & 26 \\
\hline \multirow{6}{*}{$\begin{array}{l}\text { Program } \\
\text { Studi }\end{array}$} & 1 & 57 & 54 & 111 \\
\hline & 2 & 12 & 4 & 16 \\
\hline & 3 & 12 & 19 & 31 \\
\hline & 4 & 11 & 13 & 24 \\
\hline & 5 & 68 & 95 & 163 \\
\hline & 6 & 13 & 29 & 42 \\
\hline
\end{tabular}

Analisis metode CHAID untuk faktorfaktor yang mempengaruhi waktu penyelesaian skripsi mahasiswa dengan jenis kelamin lakilaki dengan bantuan software SPSS 22.0 dapat dilihat pada diagram pohon yang disajikan pada Gambar 2.

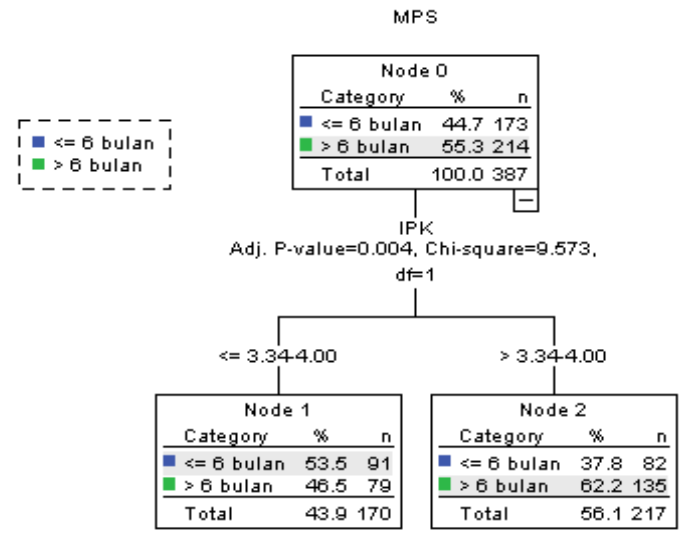

Gambar 2. Diagram Pohon Masa Penyelesaian Skripsi Mahasiswa Laki-Laki FTIK IAIN Bukittinggi

Berdasarkan Gambar 2, dari sembilan variabel bebas yang diduga akan mempengaruhi masa penyelesaian skripsi mahasiswa laki-laki hanya satu variabel bebas yang paling signifikan yaitu IPK dengan $\chi^{2}=9,573$ dan $p$-value $=0,004$. Dari 3 kategori variabel IPK yaitu,

Kategori $1: 3,34-4,00$

Kategori $2: 2,76-3,33$

Kategori 3: 2,00-2,75

Setelah dilakukan tahap pertama yaitu penggabungan pada langkah metode CHAID diperoleh segmentasi menjadi dua kategori yaitu, kategori 2 dan 3 digabung sehingga diperoleh kategor baru yaitu 2,00-2,75, 2,763,33 atau kategori IPK $<3,34$ dan kategori 1 yaitu 3,34-4,00. Pada kategori IPK 3,34-4,00 sebanyak 170 orang lulusan dan kategori IPK $<3,34$ sebanyak 217 orang lulusan atau sebesar $56,07 \%$. Selanjutnya tidak terjadi pemisahan sehingga proses dihentikan.

Pohon klasifikasi CHAID pada Gambar 3 menjelaskan lulusan FTIK IAIN Bukittinggi yang berjenis kelamin laki-laki yang telah diwisuda pada periode I sampai dengan VI dibagi atas dua segmentasi yaitu, 
Tabel 5. Segmentasi Lulusan FTIK Berjenis Kelamin Laki-Laki Hasil Analisis Metode CHAID

\begin{tabular}{lc}
\hline Segmen & \multicolumn{1}{c}{ Karakteristik } \\
\hline Ke-1 & Lulusan FTIK dengan IPK 3,34-4,00 \\
\hline Ke-2 & Lulusan FTIK dengan IPK $<3,34$ \\
\hline
\end{tabular}

Dari kedua segmen pada Tabel 5 di atas, berikut disajikan jumlah masing-masing lulusan yang masa penyelesaian skripsinya termasuk cepat atau tepat waktu ( $\leq 6$ bulan) dan kategori lambat ( $>6$ bulan) pada Tabel 6 berikut,

Tabel 6. Tabulasi Jumlah Lulusan FTIK Berjenis

Kelamin Laki-Laki Berdasarkan Masa Penyelesaian Skripsinya

\begin{tabular}{|l|l|l|l|l|}
\hline \multirow{2}{*}{ Segmen } & \multicolumn{3}{|l|}{ Masa Penyelesaian Skripsi } \\
\cline { 2 - 5 } & $\leq \mathbf{6}$ bulan & \multicolumn{1}{l|}{$\mathbf{6}$ bulan } \\
\cline { 2 - 5 } & Jumlah & $\mathbf{0}$ & Jumlah & \% \\
\hline $\mathrm{Ke}-1$ & 91 & 53,5 & 79 & 46,5 \\
\hline $\mathrm{Ke}-2$ & 82 & 46,5 & 135 & 62,2 \\
\hline
\end{tabular}

Berdasarkan Tabel 6 dapat disimpulkan bahwa kriteria lulusan FTIK berjenis kelamin laki-laki yang memiliki peluang yang cukup besar untuk dapat menyelesaikan skripsinya cepat atau tepat waktu adalah mahasiswa dengan IPK 3,34 - 4,00 yaitu sebesar 53,5 \% atau sedangkan mahasiswa yang memiliki IPK dibawah 3,34 memiliki resiko yang besar untuk menyelesaikan skripsinya lebih lama. Hal ini dapat dilihat dari 214 lulusan yang masa penyelesaian skripsinya lebih dari 6 bulan terdapat 135 orang atau $63,08 \%$ yang memiliki IPK $<3,34$ sedangkan hanya ada 79 orang atau 36,92\% yang memiliki IPK 3,34-4.00.

Pada Penelitian ini, untuk mahasiswa FTIK IAIN Bukittinggi yang berjenis kelamin laki-laki agar mampu menyelesaikan skripsi lebih cepat diharapkan untuk memiliki IPK 3,34-4,00 atau lebih menuntaskan beban perkuliahan dengan nilai yang sangat memuaskan sehingga pada saat penyelesaian skripsi dapat lebih fokus dan dapat diselesaikan dengan lebih lancar.

\section{Analisis CHAID Faktor-Faktor Yang Mempengaruhi Waktu Penyelesaian Skripsi Mahasiswa Perempuan}

Data untuk menganalisis faktor-faktor yang mempengaruhi waktu penyelesaian skripsi pada mahasiswa perempuan adalah sebanyak 1150 orang mahasiswa FTIK IAIN Bukittinggi yang telah diwisuda pada periode I sampai dengan VI, dengan mengolah data karakteristik skripsi sesuai dengan variabel bebas yang digunakan. Untuk deskripsi singkat dari data tersebut dapat dilihat pada Tabel 7

Berdasarkan Tabel 7 dapat diterangkan bahwa lebih banyak lulusan FTIK yang memiliki masa penyelesaian skripsinya lebih dari 6 bulan ( $>6$ bulan) yaitu sebanyak 600 orang atau 55,17\% sedangkan mahasiswa yang mampu menyelesaikan skripsinya lebih cepar atau tepat waktu ( $\leq 6$ bulan) adalah sebanyak 550 orang atau $44,83 \%$.

Tabel 7. Data Karakteristik Skripsi Mahasiswa Berjenis Kelamin Perempuan FTIK IAIN Bukittinggi

\begin{tabular}{|c|c|c|c|c|}
\hline \multirow{2}{*}{$\begin{array}{l}\text { variabel } \\
\text { bebas }\end{array}$} & \multirow[b]{2}{*}{ kategori } & \multicolumn{2}{|c|}{ MPS } & \multirow[b]{2}{*}{ Total } \\
\hline & & $\begin{array}{l}<=6 \\
\text { bulan }\end{array}$ & $\begin{array}{l}> \\
\text { bulan }\end{array}$ & \\
\hline \multicolumn{2}{|c|}{ Total } & 550 & 600 & 1150 \\
\hline \multirow{3}{*}{ IPK } & 1 & 288 & 291 & 579 \\
\hline & 2 & 259 & 306 & 565 \\
\hline & 3 & 3 & 3 & 6 \\
\hline \multirow{5}{*}{ JP } & 1 & 225 & 263 & 488 \\
\hline & 2 & 173 & 207 & 380 \\
\hline & 3 & 18 & 12 & 30 \\
\hline & 4 & 14 & 13 & 27 \\
\hline & 5 & 120 & 105 & 225 \\
\hline \multirow{2}{*}{ JKP 1} & 1 & 317 & 312 & 629 \\
\hline & 2 & 233 & 288 & 521 \\
\hline \multirow{2}{*}{ JKP 2} & 1 & 308 & 335 & 643 \\
\hline & 2 & 242 & 265 & 507 \\
\hline \multirow{4}{*}{ BKD 1} & 1 & 133 & 116 & 249 \\
\hline & 2 & 151 & 158 & 309 \\
\hline & 3 & 198 & 255 & 453 \\
\hline & 4 & 68 & 71 & 139 \\
\hline \multirow{3}{*}{ BKD 2} & 1 & 199 & 282 & 481 \\
\hline & 2 & 222 & 188 & 410 \\
\hline & 3 & 115 & 114 & 229 \\
\hline
\end{tabular}




\begin{tabular}{|c|c|c|c|c|}
\hline & 4 & 14 & 16 & 30 \\
\hline \multirow{4}{*}{ SD } & 1 & 275 & 390 & 665 \\
\hline & 2 & 34 & 42 & 76 \\
\hline & 3 & 126 & 54 & 180 \\
\hline & 4 & 115 & 114 & 229 \\
\hline \multirow{5}{*}{ TPD } & 1 & 136 & 137 & 273 \\
\hline & 2 & 164 & 207 & 371 \\
\hline & 3 & 86 & 58 & 144 \\
\hline & 4 & 134 & 162 & 296 \\
\hline & 5 & 30 & 36 & 66 \\
\hline \multirow{6}{*}{$\begin{array}{l}\text { Program } \\
\text { Studi }\end{array}$} & 1 & 126 & 118 & 244 \\
\hline & 2 & 32 & 8 & 40 \\
\hline & 3 & 71 & 79 & 150 \\
\hline & 4 & 88 & 102 & 190 \\
\hline & 5 & 174 & 127 & 301 \\
\hline & 6 & 59 & 166 & 225 \\
\hline
\end{tabular}

Berdasarkan Tabel 7 juga dapat disimpulkan bahwa jenis penelitian yang paling banyak diminati oleh mahasiswa perempuan adalah penelitian metode kuantitatif, sumber data penelitian paling banyak digunakan sumber primer dengan teknik pengambilan data terbanyak berupa angket. Untuk karakteristik dosen pembimbing bagi lulusan FTIK berjenis kelamin perempuan adalah sebagai berikut, jenis kelamin dosen pembimbingnya lebih banyak berjenis kelamin laki-laki dari pada berjenis kelamin perempuan baik untuk dosen pembimbing utama maupun untuk dosen pembimbing pendamping. Sedangkan untuk bidang keahlian dosen pembimbing, lebih banyak dibimbing oleh dosen dengan keahlian pendidikan umum untuk dosen pembimbing utamanya dan keahlian murni yang sesuai dengan program studi masing-masing untuk dosen pembimbing pendamping. Lulusan FTIK berjenis kelamin perempuan ini lebih banyak berasal dari program studi PTIK.

Hasil analisis metode CHAID untuk faktor-faktor yang mempengaruhi waktu penyelesaian skripsi mahasiswa FTIK IAIN Bukittinggi yang berjenis kelamin perempuan yang telah diwisuda pada periode I sampai dengan VI dengan bantuan software SPSS 22.0 dapat dilihat pada diagram pohon yang disajikan pada Gambar 3. Diagram pohon tersebut memperlihatkan bahwa dari sembilan variabel bebas yang diduga mempengaruhi masa penyelesaian skripsi mahasiswa perempuan terdapat tiga variabel bebas yang signifikan mempengaruhi variabel masa penyelesaian skripsi. Ketiga variabel tersebut berdasarkan urutan signifikansinya adalah Jur (program Studi), SD (Sumber Data) dan BKD 1 (Bidang Keahlian dosen pembimbing utama).

Tahap pertama dalam langkah-langkah metode CHAID adalah tahap penggabungan. Pada tahap ini diperoleh variabel yang paling signifikan pengaruhnya terhadap masa penyelesaian skripsi mahasiswa berjenis kelamin perempuan adalah program studi dari mahasiswa tersebut, hal ini dapat dilihat pada;

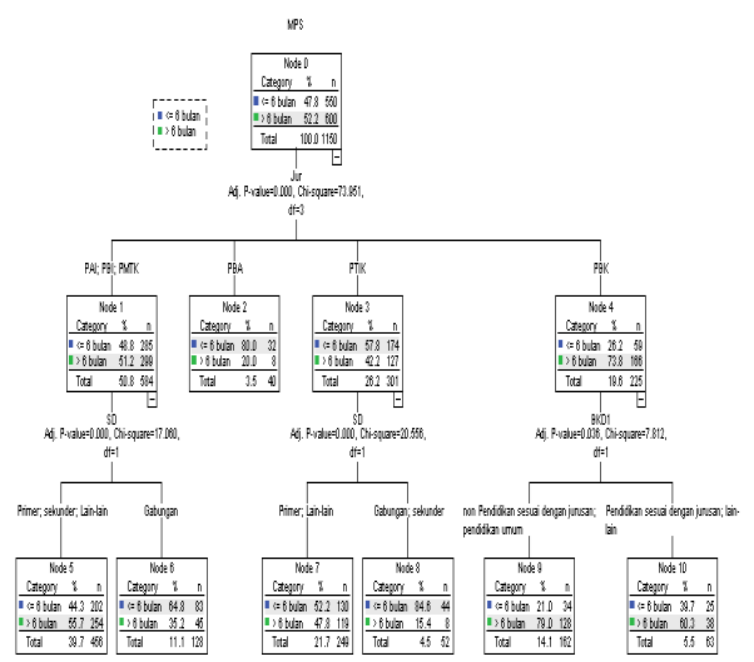

Gambar 3. Diagram Pohon Masa Penyelesaian Skripsi Mahasiswa Perempuan FTIK IAIN Bukittinggi

Gambar 3 di kedalam pertama, dimana pada variabel ini dari enam kategori setelah melakukan tahap penggabungan diperoleh 4 kategori baru, yaitu: Prodi PAI, PBI dan PMTK, Prodi PBA, Prodi PTIK, dan Prodi BK.

Kategori PAI, PBI dan PMTK digabung, hal ini berarti syarat signifikan $\chi^{2}$ untuk dapat digabung menjadi kategori tunggal. 
Setelah diperoleh predictor atau variabel bebas yang paling signifikan dan diperoleh kategori-kategori baru maka data yang belum di analisis dipartisi berdasarkan kategori-kategori baru. Variabel bebas kedua yang paling signifikan adalah sumber data (SD) pada kategori gabungan PAI, PBI, PMTK, begitu juga pada kategori PTIK sedangkan berdasarkan kategori BK variabel bebas yang paling signifikan setelah variabel jurusan adalah Bidang Keahlian Dosen Pembimbing Utama (BKD1).

Berdasarkan kategori gabungan PAI,PBI dan PMTK, variabel bebas sumber data (SD) setelah dilakukan tahap penggabungan juga mengalami kategori ulang, dari empat kategori asli menjadi dua kategori yaitu, Sumber data Primer, Sekunder dan lainlain; Sumber data gabungan.

Kategori primer, sekunder dan lain-lain mengalami penggabungan karena nilai $\chi^{2}$ memenuhi syarat untuk dijadikan sebagai kategori tunggal.

Variabel sumber data sebagai variabel kedua yang paling signifikan setelah variabel jurusan untuk kategori PTIK juga mengalami kategori ulang, dari empat kategori asli digabung sehingga diperoleh dua kategori baru yaitu, Primer dan lain-lain dan Sekunder dan gabungan.

Kedua kategori di atas masing-masing mengalami penggabungan sehingga masingmasing menjadi kategori tunggal.

Variabel bebas kedua yang berpengaruh terhadap masa penyelesaian skripsi pada kategori BK adalah bidang keahlian dosen pembimbing utama (BKD 1). Kategori BKD 1 ini dikategori ulang menjadi dua kategori yaitu, latar belakang pendidikan dosen non pendidikan yang sesuai dengan program studi digabung dengan pendidikan umum dan latar belakang pendidikan dosen pendidikan sesuai dengan program studi yang diampu digabung dengan latar belakang pendidikan lain-lain.
Berdasarkan Gambar 3, pohon klasifikasi metode CHAID mempunyai 2 kedalam dengan 11 node dan 7 diantaranya sebagai terminal node. Node 5, 6, 7 dan 9 dihentikan karena setelah dipartisi data lainnya berdasarkan node ini tidak ada lagi variabel bebas yang signifikan terhadap variabel terikat. Sedangkan untuk node 2 dihentikan karena memiliki data yang sedikit dan tidak memenuhi syarat untuk jumlah minimum cbild node disamping itu tidak ada lagi variabel bebas yang signifikan terhadap variabel terikat. Untuk node 8 dan 10 mengalami proses penghentian karena jumlah pengamatan tidak mencukupi jumlah minimum kasus parent node dan jumlah minimum child nodenya.

Analisis metode CHAID untuk faktorfaktor yang mempengaruhi masa penyelesaian skripsi mahasiswa FTIK IAIN Bukittinggi berjenis kelamin perempuan menghasilkan tujuh kriteria lulusan dan memiliki dugaan masa penyelesaian skripsi masing-masingnya yang disajikan secara lengkap pada Tabel 8 berikut,

Tabel 8. Segmentasi Lulusan FTIK Berjenis Kelamin Perempuan Hasil Analisis Metode CHAID

\begin{tabular}{|c|c|c|}
\hline $\begin{array}{l}\text { Seg } \\
\text { men }\end{array}$ & Karakteristik & $\begin{array}{l}\text { Dugaan } \\
\text { Waktu } \\
\text { MPS }\end{array}$ \\
\hline $\mathrm{Ke}-1$ & $\begin{array}{l}\text { Lulusan FTIK dengan prodi } \\
\text { PAI/PBI/ PMTK dengan sumber } \\
\text { data } \\
\text { primer/sekunder/lain-lain. }\end{array}$ & $>6$ bulan \\
\hline $\mathrm{Ke}-2$ & $\begin{array}{l}\text { Lulusan FTIK dengan prodi } \\
\text { PAI/PBI/ PMTK dengan sumber } \\
\text { data penelitian gabungan. }\end{array}$ & $\leq 6$ bulan \\
\hline $\mathrm{Ke}-3$ & Lulusan FTIK dengan prodi PBA & $\leq 6$ bulan \\
\hline $\mathrm{Ke}-4$ & $\begin{array}{l}\text { Lulusan FTIK dengan prodi PTIK } \\
\text { dengan sumber data penelitian } \\
\text { primer/gabungan }\end{array}$ & $\leq 6$ bulan \\
\hline $\mathrm{Ke}-5$ & $\begin{array}{l}\text { Lulusan FTIK dengan prodi PTIK } \\
\text { dengan sumber data penelitian } \\
\text { gabungan/sekunder }\end{array}$ & $\leq 6$ bulan \\
\hline $\mathrm{Ke}-6$ & $\begin{array}{l}\text { Lulusan FTIK dengan prodi BK } \\
\text { yang dibimbing oleh dosen } \\
\text { pembimbing utama yang memiliki } \\
\text { latar belakang pendidikan non } \\
\text { pendidikan sesuai dengan } \\
\text { prodi/pendidikan umum }\end{array}$ & $>6$ bulan \\
\hline $\mathrm{Ke}-7$ & $\begin{array}{l}\text { Lulusan FTIK dengan prodi BK } \\
\text { yang dibimbing oleh dosen } \\
\text { pembimbing utama yang memiliki }\end{array}$ & $>6$ bulan \\
\hline
\end{tabular}




\begin{tabular}{lr}
\hline $\begin{array}{l}\text { latar belakang } \\
\text { pendidikan sesuai } \\
\text { prodi/lain-lain. }\end{array}$ & dengan \\
\hline
\end{tabular}

Dari ke-7 kriteria terdapat empat kriteria yang diduga mampu menyelesaikan skripsinya cepat atau tepat waktu yaitu; Lulusan FTIK dengan prodi PAI/PBI/ PMTK dengan sumber data penelitian gabungan; Lulusan FTIK dengan prodi PBA; Lulusan FTIK dengan prodi PTIK dengan sumber data penelitian primer/gabungan; Lulusan FTIK dengan prodi PTIK dengan sumber data penelitian gabungan/sekunder.

Sedangkan tiga karakteristik lainnya memiliki peluang yang lebih besar untuk lebih lambat dalam penyelesaian skripsinya.

Selanjutnya akan dilakukan analisis hasil dari metode CHAID ini berdasarkan sebaran atau distribusi data terhadap masa penyelesaian skripsinya. Tabel 9 berikut memperlihatkan distribusi masa penyelesaian skripsi untuk setiap kelompoknya atau karakteristiknya.

Tabel 9. Distribusi Masa Penyelesaian Skripsi Dari Pohon Klasifikasi Metode CHAID Untuk Lulusan FTIK Berjenis Kelamin Perempuan Periode I - VI

\begin{tabular}{|c|c|c|c|}
\hline \multirow{2}{*}{$\begin{array}{l}\text { Kelompok } \\
\text { Ke- }\end{array}$} & \multirow{2}{*}{$\begin{array}{l}\text { Simpul } \\
\text { Akhir }\end{array}$} & \multicolumn{2}{|c|}{ Penyelesaian } \\
\hline & & $\leq 6$ bulan & $>6$ bulan \\
\hline 1 & 5 & $\begin{array}{l}202 \\
36,7 \%\end{array}$ & $\begin{array}{l}254 \\
42,3 \%\end{array}$ \\
\hline 2 & 6 & $\begin{array}{l}83 \\
15,1 \%\end{array}$ & $\begin{array}{l}45 \\
7,5 \%\end{array}$ \\
\hline 3 & 2 & $\begin{array}{l}32 \\
5,8 \%\end{array}$ & $\begin{array}{l}8 \\
1,3 \%\end{array}$ \\
\hline 4 & 7 & $\begin{array}{l}130 \\
23,6 \%\end{array}$ & $\begin{array}{l}119 \\
19,8 \%\end{array}$ \\
\hline 5 & 8 & $\begin{array}{l}44 \\
8 \%\end{array}$ & $\begin{array}{l}8 \\
1,3 \%\end{array}$ \\
\hline 6 & 9 & $\begin{array}{l}34 \\
6,2 \%\end{array}$ & $\begin{array}{l}128 \\
21,3 \%\end{array}$ \\
\hline 7 & 10 & $\begin{array}{l}25 \\
4,5 \%\end{array}$ & $\begin{array}{l}38 \\
6,3 \%\end{array}$ \\
\hline
\end{tabular}

Dari Tabel 9 dapat disimpulkan bahwa dari 550 orang mahasiswa FTIK berjenis kelamin perempuan yang mampu menyelesaikan skripsi dalam rentang waktu kurang atau sama dengan 6 bulan, maka distribusi terbesar terdapat pada kelompok ke1 yaitu lulusan FTIK dengan prodi PAI/PBI/ PMTK dengan sumber data penelitian primer/sekunder/lain-lain sebanyak 202 orang atau $36,7 \%$ dan terbesar kedua terdapat pada kelompok ke-4 yaitu lulusan FTIK yang berasal pada prodi PTIK dengan sumber data penelitian berupa data primer atau gabungan sebanyak 130 orang atau $23,6 \%$.

Untuk lulusan FTIK yang menyelesaikan skripsi lebih dari enam bulan, distribusi terbesar terdapat pada kelompok ke1 yaitu lulusan FTIK dengan prodi PAI/PBI/ PMTK dengan sumber data penelitian primer/sekunder/lain-lain sebanyak 254 orang dari total 600 orang mahasiswa atau sekitar $42,3 \%$, selanjutnya terdapat pada kelompok ke6 yaitu lulusan FTIK dengan prodi BK yang dibimbing oleh dosen pembimbing utama yang memiliki latar belakang pendidikan non pendidikan sesuai dengan prodi/pendidikan umum yaitu sebanyak 128 orang mahasiswa atau $21,3 \%$.

Pada penelitian ini dari tujuh karakteristik lulusan FTIK yang berjenis kelamin perempuan terdapat tiga karakteristik mahasiswa yang diduga untuk lebih lama dalam menyelesaikan skripsinya, yaitu

Karakteristik ke-1, Lulusan FTIK dengan prodi PAI/PBI/PMTK dengan sumber data penelitian primer/sekunder/lainlain. Bagi mahasiswa dengan karakteristik seperti ini biasanya penelitian yang dilakukan merupakan penelitian dengan pendekatan kuantitatif, dimana penelitian yang dilakukan bisa berupa eksperimen atau korelasional yang cenderung pengambilan datanya berupa data primer dan atau data sekunder. Sedangkan untuk mahasiswa dengan sumber data lain-lain biasanya paling banyak terdapat pada mahasiswa PAI yang penelitiannya berupa studi pustaka. Mahasiswa dengan karakteristik ini diharapkan agar lebih disiplin dalam melaksanakan penelitian karena terkait dengan 
jadwal yang ada di sekolah tempat penelitian berlangsung sedangkan bagi penelitian studi literatur agar lebih memanfaat kan e-book sebagai salah satu sumber literatur atau lebih memanfaatkan perpustakaan online sehingga kendala-kendala dalam pengumpulan teori yang cukup dan akurat dapat dihindari sehingga peluang dalam penyelesaian skripsi lebih dari 6 bulan dapat diminimalisir.

Dua karakteristik berikutnya adalah karakteristik ke-6 dan ke-7 yaitu lulusan FTIK dengan prodi $\mathrm{BK}$ baik yang dibimbing oleh dosen pembimbing utama yang memiliki latar belakang non pendidikan sesuai dengan prodi/ pendidikan umum maupun latar belakang pendidikan sesuai dengan prodi/lain-lain. Berdasarkan distribusi data, dari 166 orang lulusan prodi BK yang masa penyelesaian skripsinya lebih dari 6 bulan terdapat 128 orang atau 77,1 memiliki karakteristik ke-6, yaitu mahasiswa yang dibimbing oleh dosen pembimbing utama dengan keahlian non pendidikan sesuai dengan program studi seperti psiokolog/ keahlian lain-lain, seperti sosiologi, filsafat dan lain-lain. Bagi mahasiswa ini agar memiliki referensi yang lebih banyak sehingga keakuratan teori yang sesuai dengan judul penelitian dapat dipertanggung jawabkan dan lebih disiplin dalam melakukan bimbingan sehingga masa penyelesaian skripsinya bisa lebih cepat atau tepat waktu.

Jadi pada mahasiswa perempuan FTIK yang telah diwisuda pada periode I sampai dengan VI faktor-faktor yang mempengaruhi masa penyelesaian skripsi adalah program studi dari mahasiswa tersebut, sumber data dan bidang keahlian dosen pembimbing utama. Hal ini selaras dengan teori bahwa "anak perempuan lebih mampu dalam beberapa keterampilan verbal" dan "anak perempuan lebih tinggi dalam membaca dan kajian sosial"16 serta " wanita memiliki kelebihan dalam hal

${ }^{16}$ John W. Santrock., (2014), Psikologi Pendidikan (edisi 5 Buku 1), Jakarta:Salemba Humatika, h 186-187. mengerjakan tes-tes yang menyangkut penggunaan bahasa, hafalan-hafalan, reaksireaksi estetika serta masalah-masalah sosial" ${ }^{\text {"17 }}$. Sehingga hal ini menjadi alasan logis bahwa program studi dan sumber data menjadi salah satu faktor yang mempengaruhi masa penyelesaian skripsi bagi mahasiswa perempuan. Begitu juga halnya dengan faktor bidang keahlian dosen pembimbing utama, dimana menurut Maria Polina dan Jok Jiang Siang faktor terkait dengan dosen pembimbing merupakan salah satu faktor eksternal yang mampu mempengaruhi penyelesaian skripsi.

\section{Kesimpulan}

Dari uraian di atas, dapat ditarik kesimpulan bahwa berdasarkan analisis metode CHAID; Bagi mahasiswa FTIK yang berjenis kelamin laki-laki faktor yang mempengaruhi masa penyelesaian skripsinya adalah IPK. Faktor-fakor yang mempengaruhi masa penyelesaian skripsi bagi mahasiswa FTIK yang berjenis kelamin perempuan adalah Program studi, Sumber data dan bidang keahlian dosen pembimbing utama.

Terdapat dua karakteristik lulusan FTIK berjenis kelamin laki-laki, yaitu; lulusan FTIK dengan IPK 3,34-4,00; lulusan FTIK dengan IPK kurang dari 3,34.

Tujuh karakteristik lulusan FTIK berjenis kelamin perempuan, diantaranya; Lulusan FTIK dengan prodi PAI/PBI/ PMTK dengan sumber data primer/sekunder/lain-lain; Lulusan FTIK dengan prodi PAI/PBI/ PMTK dengan sumber data gabungan; Lulusan FTIK dengan prodi PBA; Lulusan FTIK dengan prodi PTIK dengan sumber data primer/gabungan; Lulusan FTIK dengan prodi PTIK dengan sumber data sekunder/lain-lain; Lulusan FTIK dengan prodi BK yang dibimbing oleh dosen pembimbing utama dengan bidang keahlian non pendidikan sesuai dengan prodi

17 Wasty Soemanto.(2006).Psikologi Pendidikan: Landasan Kerja Pemimpin Pendidikan. H 157 
(psikolog)/ lain-lain; Lulusan FTIK dengan prodi $\mathrm{BK}$ yang dibimbing oleh dosen pembimbing uatam dengan bidang keahlian sesuai dengan prodi (BK)/ pendidikan umum.

Untuk meminimalisir masa penyelesaian skripsi yang tidak tepat waktu atau lebih dari 6 bulan, diharapkan kedisiplinan dan kerja keras yang lebih untuk kriteria mahasiswa laki-laki dengan IPK $<3,34$, mahasiswa perempuan prodi PAI/PBI/PMTK dengan sumber data primer/sekunder/ lain-lain dan mahasiswa perempuan prodi BK yang dibimbingan oleh dosen pembimbing utama dengan latar belakang pendidikan psikologi/lain-lain.

\section{Daftar Kepustakaan}

\section{Buku Teks}

Anggraini, Asih. dkk, (2006), Mengasah Keterampilan Menulis Ilmiah di Perguruan Tinggi, Yogyakarta: Graha Ilmu.

IAIN Bukittinggi, (2015), Pedoman Penulisan Tugas Akhir dan Skripsi, Bukittinggi: LPM IAIN Bukittinggi.

Ormrod, Jeanne Ellis (2008), Psikologi Pendidikan, Jakarta: Erlangga.

Polina, Agnes Maria, Jong Jek Siang (2009), Cara Cepat Menyusun Skripsi Yogyakarta: Andi.

Riadi, Edi (2016), Statistika Penelitian (Analisis Manual dan IBM SPSS), Yogyakarta: Andi.

Santrock, John W, (2014), Psikologi Pendidikan (Edisi 5 Buku 1), Jakarta: Salemba Humatika.

Soemanto, Wasty, (2006), Psikologi Pendidikan (Edisi 5 Buku 1), Landasan Kerja Pemimpin Pendidikan.

\section{Jurnal Ilmiah}

Kunto, Yohanes Sondang dan Siti Nurul Hasana, Analisis CHAID Sebagai Alat Bantu Statistika Untuk Segmentasi Pasar, Jurnal Manajemen Pemasaran, Vol. 1, No. 2, h.89

Makalah Ilmiah dan Artikel

S. Dian Cahyawati, dkk, Aplikasi Metode CHAID dalam Menganalisis Keterkaitan Faktor Resiko Lama Penyelesaian Skripsi
Mahasiswa, Prosiding, Seminar Nasional Matematika dan Pendidikan Matematika dengan tema "Penguatan Peran Matematika dan Pendidikan Matematika untuk Indonesia yang Lebih Baik" pada tanggal 9 November 2013 di Jurusan PMTK FMIPA UNY, h. 47.

\section{Referensi Online}

Gallagher, Cecily A, dkk, "an Iterative Approach To Classification Analysis", http://www.Casact.org/pubs/dpp/dpp 90/90dpp237. pdf diakses 13 maret 2017. h242

Lehmann, Dietrich Eherler \& Thomas. Responder Profiling with CHAID and Dependency Analysis.

https://pdfs.semanticscholar.org/4536/a9350 179566c6e47b0ff9b283457aa6c75b0.pdf. diakses tanggal 13 Agustus 2018. 